\title{
Meibomian Gland Absence Related Dry Eye in Ectodysplasin A Mutant Mice
}

\author{
Yen-Chiao Wang, ${ }^{* \dagger \ddagger}$ Sanming Li, ${ }^{* \dagger \ddagger}$ Xiaoxiao Chen, ${ }^{* \dagger \ddagger}$ Baikai Ma, ${ }^{* \dagger \ddagger}$ Hui He, ${ }^{* \dagger \ddagger}$ Tingting Liu, ${ }^{* \dagger \ddagger}$ Jingwen Yu, ${ }^{* \dagger \ddagger}$ \\ Liying Zhang, ${ }^{* \dagger}$ Yongxiong Chen, ${ }^{* \dagger}$ Zuguo Liu, ${ }^{\star \dagger \ddagger \delta}$ and Wei Li* ${ }^{* \dagger ई \delta}$
}

From the Eye Institute of Xiamen University, * Xiamen; the Department of Ophthalmology \& Visual Science, ${ }^{\dagger}$ Medical College of Xiamen University, Xiamen; the Fujian Provincial Key Laboratory of Ophthalmology and Visual Science, ${ }^{\ddagger}$ Xiamen, Fujian; and the Department of Corneal \& Ocular Surface Diseases, ${ }^{\S}$ Xiamen University Affiliated Xiamen Eye Center, Xiamen, China

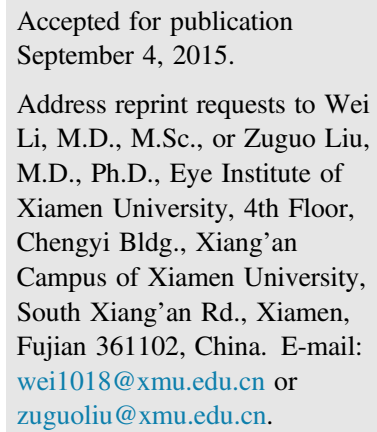

\begin{abstract}
Meibomian gland dysfunction is the most frequent cause of evaporative dry eye, yet its underlying pathophysiology is unknown. To gain insight into this pathophysiology, we characterized the timedependent tear film and ocular surface changes occurring in X-linked anhidrotic-hypohidrotic ectodermal dysplasia mice (Tabby), which lack the meibomian gland. These mice sequentially developed corneal epithelial defects, central corneal stromal edema, neovascularization, and pannus 8 to 16 weeks after birth. Aqueous tear secretion was normal, whereas tear break-up time and ex vivo tear evaporation times were all shortened. Corneal epithelial microvilli were less numerous, conjunctival goblet cell density was unaffected, and MUC5AC and MUC5B gene expression was increased. Markers of squamous metaplasia (cytokeratin 10 and small proline-rich protein 1B) were noticed in the corneal epithelium of Tabby mice as early as the fourth week. Taken together, the Tabby mouse is a relevant meibomian gland dysfunctionrelated dry eye model that may lead to a better understanding of how meibomian glands are related to ocular surface health. This model may also help with discovering novel drug options for treating evaporative dry eye. (Am J Pathol 2016, 186: 32-42; http://dx.doi.org/10.1016/j.ajpath.2015.09.019)
\end{abstract}

Meibomian glands (MGs) are modified large sebaceous glands embedded in the tarsal plate of the eyelids. ${ }^{1}$ Their secretions, that is, meibum, consist of a complex mixture of various polar and nonpolar lipids ${ }^{2}$ and $>90$ different proteins. ${ }^{3}$ The meibum lipids spread onto the tear film and smooth the corneal surface, which stabilizes and reduces tear film evaporation. Moreover, tear lipids also form a barrier to protect the eye from microbial infections. ${ }^{4}$

MG dysfunction (MGD) is a chronic and diffuse abnormality of the MGs, commonly characterized by terminal duct obstruction and/or possible qualitative/quantitative changes in the glandular secretion. ${ }^{5}$ MGD may cause tear film instability and increase tear evaporation, resulting in symptoms such as eye irritation and clinically apparent inflammation. ${ }^{5}$ It is now well accepted that MGD is the most common cause of evaporative dry eye. ${ }^{6-9}$ Hence, more attention is being paid to the effect of MGD on changes in ocular surface integrity.

Many human generated and naturally occurring MGD animal models exist such as those generated by cauterization of the MG orifices, ${ }^{10}$ topical application of epinephrine, ${ }^{11-13}$ systemic administration of isotretinoin, ${ }^{14}$ and polychlorinated biphenyl poisoning. ${ }^{15}$ The genetic mutant mice that showed abnormal MGs include ACAT1 gene, ${ }^{16}$ tumor necrosis factor receptorassociated factor 6 deficiency, ${ }^{17}$ CCAAT/enhancer binding protein $\alpha$ and $\beta,{ }^{18}$ ectodysplasin-A and its receptor, ${ }^{19}$ bone morphogenetic protein signaling, ${ }^{20,21}$ homeodomain transcription factor BARX2, ${ }^{22}$ kruppel-like factor $5,{ }^{23}$ and fatty acid transport protein 4 mutation. ${ }^{24}$ The transgene models include mice overexpressing apolipoprotein $\mathrm{C} 1$ gene $^{25}$ and with deletion of stearoyl-CoA desaturase 1 gene. ${ }^{26,27}$ Both types of models show abnormal development, atrophy, or dystrophy of MGs. Most of these animal model studies focused on pathology or pathophysiology of the MG per se; however, the contribution

Supported in part by the Chinese National Key Scientific Research Project grant 2013CB967003, the National Natural Science Foundation of China grants 81270977 and 81470602 , Chinese National Health and Family Planning Commission Project WKJ-FJ-26, and the Fundamental Research Funds for the Central Universities of China grant 2012121049 and 20720150171 (W.L.).

Y.-C.W., S.L., and X.C. contributed equally to this work as first authors. Disclosures: None declared. 
of MG atrophy or dystrophy to the development of ocular surface abnormalities in these mice remains largely unknown.

The X-linked anhidrotic-hypohidrotic ectodermal dysplasia mouse (Tabby) is a naturally developed ectodysplasin A (EDA) mutant strain. ${ }^{28}$ Besides having abnormalities in skin appendages and teeth development, this strain also lacks MGs. ${ }^{29}$ This strain represents an extreme MGD condition in which no secretions spread onto the ocular surface. Therefore, through evaluating the ocular surface pathophysiologic changes in this model, it is possible to obtain additional insight into the contribution made by MG secretory activity to ocular surface health.

The changes in ocular surface phenotype of Tabby mice include corneal epithelial defects, keratitis, corneal ulceration, neovascularization, keratinization, blepharitis, and conjunctivitis. ${ }^{19}$ However, most observations focused on the late stage from 12 to 36 weeks, when corneal pathology became prominent. There are no reports at any time during development about any tear film changes and their association with ocular surface pathology. We describe here the ocular surface changes occurring between 4 and 16 weeks after birth in Tabby mice. The results indicate that at the early interval from 6 to 8 weeks changes are already occurring similar to those seen in evaporative dry eye disease. The appearance of changes at this early age suggests that they may also be a valuable model to gain insight into the contribution of MGD to the pathophysiologic changes underlying evaporative dry eye disease.

\section{Materials and Methods}

\section{Animals}

EDA mutant Tabby mice $($ Eda $<$ Ta- $6 \mathrm{~J}>/ \mathrm{Y}$ ) and wild-type C57BL/6J mice, originally purchased from The Jackson Laboratory (Bar Harbor, ME), were used in this study. The mice were kept in standard pathogen-free environment at $25^{\circ} \mathrm{C} \pm 1{ }^{\circ} \mathrm{C}$, relative humidity $60 \% \pm 10 \%$, and alternating 12 hours light-dark cycles (8:00 AM to 8:00 PM). All procedures were performed in accordance with the Association for Research in Vision and Ophthalmology Statement for the Use of Animals in Ophthalmic and Vision Research. ${ }^{30}$ This study received the approval of the Animal Ethical Committee of Xiamen University. In total, 30 male Tabby mice and 30 male wild-type mice were used in this study. Among them, six Tabby mice and six wild-type mice were used for ocular surface observation and assessment. Others were sacrificed at ages of 4, 5, 6, 7, 8, 10,12, and 16 weeks, with three animals at each time point. The eyelid, eyeball, and lacrimal gland tissues from both sides were harvested for histology, immunostaining, or RNA extraction.

\section{Tear Secretion Measurement}

Aqueous tear volume was measured with phenol red thread (ZONE-QUICK; Yokota, Tokyo, Japan) tear secretion test at 3:00 PM in the standard environment with modification. ${ }^{31}$
In brief, the lower eyelid was pulled down slightly, and $10 \mathrm{~mm}$ of the thread was placed on the palpebral conjunctiva one-third of the distance away from the lateral canthus of the lower eyelid for 15 seconds. The values indicated by the red color position of the aqueous front on the thread were recorded in millimeters.

\section{Slit-Lamp Microscopy Evaluation}

Anterior and lateral views of the mice eyeballs were observed under a slit-lamp microscope (Kanghua Science \& Technology Co., Ltd., Chongqing, China). After that, $1 \mu \mathrm{L}$ of $0.1 \%$ liquid sodium fluorescein (Jingmingxin Co., Ltd., Tianjin, China) was dropped into the conjunctival sac. After three compulsory blinks, tear break-up time (TBUT) was recorded in seconds as previously reported. ${ }^{31}$ Ninety seconds later, corneal epithelial fluorescein staining was recorded under the slit-lamp microscope with a cobalt blue filter. For grading of the fluorescein staining, the cornea was divided into four quadrants, staining was scored separately, and the scores of four quadrants were summed and analyzed. ${ }^{31}$

\section{Ex Vivo Tear Evaporation Assay}

One microliter of phosphate buffer $[0.1 \mathrm{~mol} / \mathrm{L}$ phosphatebuffered saline (PBS), pH7.4] was dripped onto the ocular surface of 8-week-old mice. After 1 minute, $0.5 \mu \mathrm{L}$ of diluted tears mix was collected with a micropipette and dripped onto a glass slide. The same PBS volume was used as a control. The tear smear was then observed under a microscope, and the time required for crystal formation was recorded as ex vivo tear evaporation time. The images of tear smears were taken before and after crystallization. This assay was conducted at $22.4^{\circ} \mathrm{C}$ and relative humidity of $48.6 \%$ in a stable environment.

\section{Ultra-Microstructure of Corneal Epithelium}

Scanning electron microscopy was performed to observe the surface ultra-microstructure of the corneal epithelium. In brief, diced central cornea blocks of $1 \mathrm{~mm}^{2}$ were carefully dissected, then immediately fixed by $2.5 \%$ glutaraldehyde for 2 hours. After three washes with PBS for 10 minutes each, tissues were further fixed in osmic acid for another 2 hours. After three additional washes with PBS for 10 minutes each, tissue was dehydrated with ethanol and acetone for 2 hours, and then tertiary butanol for 30 minutes at room temperature. Afterward, they were soaked in tertiary butanol at $4{ }^{\circ} \mathrm{C}$ for 16 hours, followed by drying them in a vacuum evaporator. Finally, the surface of the samples was sprayed with a metallic film and observed under a JSM6390 scanning electron microscope (JEOL, Tokyo, Japan).

\section{Evaluation of Goblet Cell Distribution}

Periodic acid-Schiff staining was performed to evaluate the distribution of goblet cells in conjunctival tissue. Each paraffin 
Table 1 Mouse Primer Sequences Used for Quantitative Real-Time PCR

\begin{tabular}{|c|c|c|}
\hline Gene & Sense primer & Antisense primer \\
\hline SPRR1B & 5'-GCGACCACACTACCTGTCCT-3' & 5'-CTGGCAAGGCTGTTTCACTT-3' \\
\hline K10 & 5'-TCGAGGACCTTAAGGGGCAG-3' & $5^{\prime}$-GTCAGCTCATCCAGTACCCTG-3' \\
\hline MUC5AC & 5'-ACACATGTTCTGGAGGGCA-3' & $5^{\prime}$-АCACTTTCGCAGCTCAACCA-3' \\
\hline MUC5B & 5'-GGAATGGGGGCTGTATTGCT-3' & 5'-CAGGGCTTGTTGGTGCATTC-3' \\
\hline MUC1 & 5'-CCCAGGACACCTACCATCCT-3' & $5^{\prime}$-ACTGCCATTACCTGCCGAAA- $3^{\prime}$ \\
\hline MUC15 & 5'-CCTGGGTGCTTCACTGCTTA-3' & $5^{\prime}-$ TGGTGCATTGTCTAATCGCAG-3' \\
\hline ACTB & 5'-GCTATTTGGCGCTGGACTT-3' & 5'-GCGGCTCGTAGCTCTTCTC-3' \\
\hline
\end{tabular}

section was deparaffinized twice in xylene for 15 minutes and rehydrated four times in ethanol for 5 minutes. After rinsing with deionized water for 10 minutes, sections were stained in periodic acid alcohol for 10 minutes. After a 10-minute rinse with deionized water, sections were stained in Schiff reagent (Leica Biosystems, Nussloch, Baden, Germany) for $10 \mathrm{mi}-$ nutes. After three rinses first with sulfurous acid for 2 minutes and then tap water for 15 minutes, each section was dehydrated four times in ethanol for 2 minutes and twice in xylene for 2 minutes. Finally, sections were mounted with the use of mounting medium.

\section{Evaluation of MG Secretion}

Oil Red O staining was conducted to evaluate the lipid secretion of the MG. Briefly, frozen eyelid sections were immediately fixed in $4 \%$ paraformaldehyde for 5 minutes, washed in PBS for 5 minutes, and stained for 7 minutes in filtered Oil Red $\mathrm{O}$ solution that was freshly prepared by mixing the stock solution $(0.8 \%$ Oil Red O in $98 \%$ isopropyl alcohol) and distilled water at a ratio of 1.5 to 1 , followed by washing in PBS for 5 minutes. Sections were then counterstained with hematoxylin and mounted in $90 \%$ glycerol.

\section{Gene Expression in Corneal and Conjunctival Tissues}

Real-time PCR was performed to detect gene expression in corneal epithelium and conjunctival tissues. Total RNA was extracted from mouse corneal epithelia and conjunctival tissues with the use of TRIzol (Invitrogen, Carlsbad, CA) and was reverse-transcribed to cDNA with the use of the ExScript RT Reagent kit (Takara, Dalian, China). The primers used to amplify specific gene products are listed in Table 1. Real-time PCR was performed with a StepOne Real-Time PCR detection system (Applied Biosystems, Darmstadt, Germany) with the use of a SYBR Premix Ex Taq Kit (Takara) according to the manufacturer's instructions. The amplification program included an initial denaturation step at $95^{\circ} \mathrm{C}$ for 10 minutes, followed by denaturation at $95^{\circ} \mathrm{C}$ for 10 seconds and annealing and extension at $60^{\circ} \mathrm{C}$ for 30 seconds for 40 cycles. The results of relative quantitative real-time PCR were analyzed by the comparative threshold cycle method and normalized to $\beta$-actin expression as an internal control.

\section{Phenotype Evaluation of Corneal and Conjunctival Epithelia}

Immunofluorescence staining on K12, K10, small proline-rich protein 1B (SPRR1B), and mucin (MUC) 5AC was performed to evaluate the phenotypic change of corneal and conjunctival epithelia in Tabby mice. Cryostat sections $(4 \mu \mathrm{m})$ of mice eyeballs and eyelid tissues of different ages from 4 to 8 weeks were fixed in acetone for 10 minutes at $-20^{\circ} \mathrm{C}$. Sections were rehydrated in PBS and then incubated in $0.2 \%$ Triton X-100 for 10 minutes. After rinsing sections three times with PBS for 5 minutes each and preincubating with $2 \%$ bovine serum albumin to block nonspecific staining for 60 minutes, sections were incubated with anti-K12 (sc-17101; Santa Cruz Biotechnology, Inc., Dallas, TX), anti-K10 (ab24638; Abcam, Cambridge, MA), anti-SPRR1B (LS-C146187; Lifespan Bioscience, Seattle, WA), and anti-MUC5AC (sc-16902; Santa Cruz Biotechnology, Inc.) antibodies (all dilution 1:50) at $4^{\circ} \mathrm{C}$ overnight. After three washes with PBS for 5 minutes, they were then incubated with Alexa Fluor 594-conjugated IgG (dilution 1:300; A11058) or Alexa Fluor 488-conjugated IgG (dilution 1:300; A11055, A21206; Life Technologies, Carlsbad, CA) for 60 minutes. After three additional PBS washes for 5 minutes, they were counterstained with DAPI, mounted, and photographed with the use of a confocal laser scanning microscope (Fluoview 1000; Olympus, Tokyo, Japan).

\section{Statistical Analysis}

Statistical analysis was performed with SPSS 16.0.0 (SPSS Inc., Chicago, IL). Summary data are reported as means \pm SD. Independent Sample $t$-test and one-way analysis of variance were applied to evaluate significance between groups. $P<0.05$ was considered statistically significant.

\section{Results}

Ocular Surface Manifestations in Tabby Mice

Wild-type corneas remained transparent with a normal ocular surface throughout the observation period from 4 to 16 weeks. However, scabrous corneal surface reflection was 

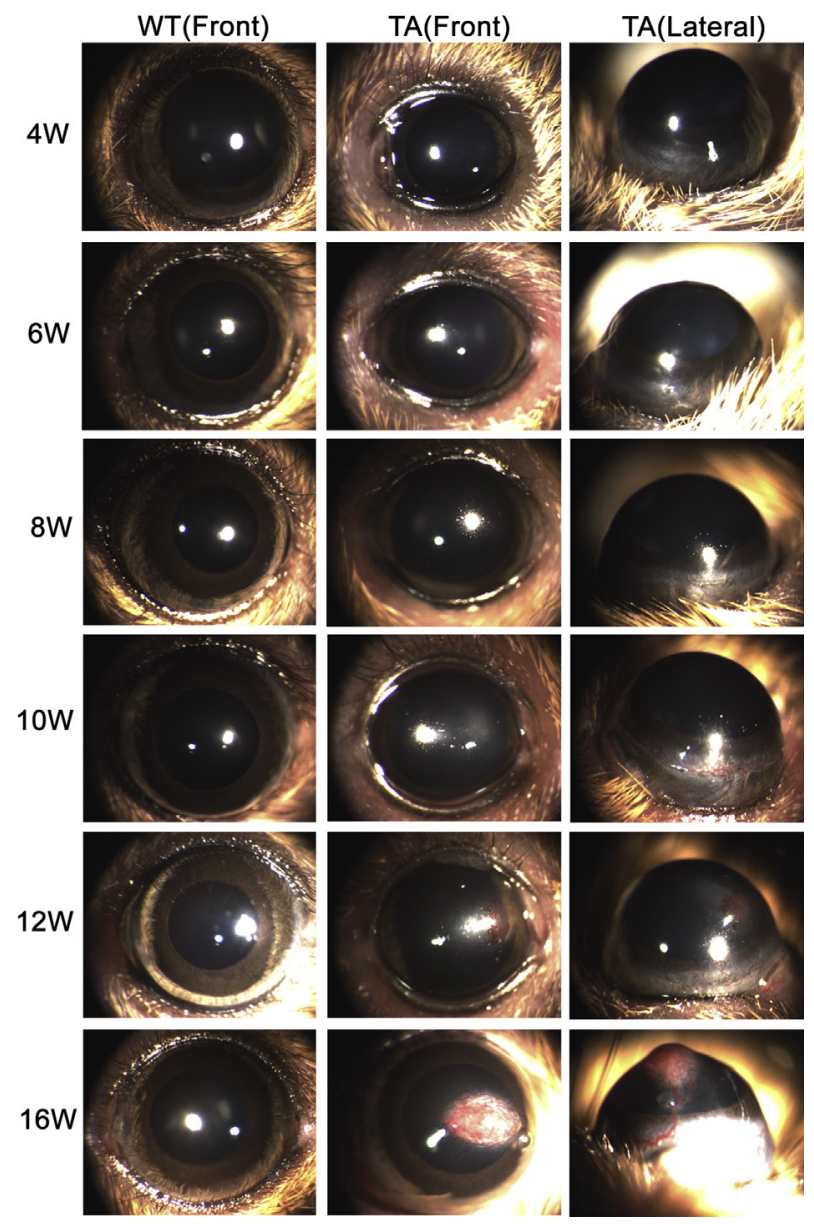

Figure 1 Slit-lamp microscope images of ocular surface of the WT and TA mice. WT mice have transparent corneas and normal ocular surface from 4 to 16 weeks [WT (Front)]. There is scabrous corneal surface reflection in TA mice from 8 to 16 weeks. Central corneal stroma has mild edema at 8 weeks, which increases at 10 weeks. New blood vessels appear in the pericentral cornea at 12 weeks, and pannus formation is evident in the central cornea at 16 weeks [TA (Front)]. Lateral view of the TA mouse eye shows congestion and ingrowth of the limbal blood vessels at 10 weeks. The new blood vessels reach the corneal edematous area at 12 weeks and form pannus tissue at 16 weeks [TA (Lateral)]. TA, Tabby; W, week; WT, wild-type.

seen in 6-week-old Tabby mice. Their central or pericentral corneal stromal regions became mildly edematous at 8 weeks of age. Neovascularization of the edematous regions became evident at 12 weeks of age, followed by pannus formation in the central cornea at 16 weeks. In a lateral eyeball view, congestion and ingrowth of the limbal blood vessels was seen at 10 weeks that were mainly distributed in the corneal edematous area at 12 weeks and accompanied by pannus tissue formation in 16-week-old mice (Figure 1).

Fluorescein staining of the Tabby mice cornea was scarce at 4 and 6 weeks; however, it progressively increased from weeks 8 to 12 . By approximately 16 weeks, a staining mass could be easily found under the slit-lamp microscope (Figure 2A). However, the fluorescein staining was restricted at most to just one quadrant in the wild-type mice from 4 to 16 weeks (data not shown). The fluorescein score was dramatically different between the Tabby mice and their age-matched wild-type counterparts at all of the time points from 8 to 16 weeks (Figure 2B).

\section{Tear Secretion and Stability Changes}

Phenol red thread tear secretion test results in Tabby mice whose ages ranged from 4 to 16 weeks indicate that aqueous tear secretion remained relatively stable with only a transient increase at 10 weeks (Figure 3A). Lacrimal gland hematoxylin and eosin staining of 8-week-old mice showed no obvious structural difference between wild-type mice (Figure 3C) and Tabby mice (Figure 3D). These negative effects indicate that the declines in ocular surface integrity were not attributable to disruption of either lacrimal gland secretory activity or structure.

Tear film stability was invariant in wild-type mice throughout the first 16 weeks of their life. From 4 to 16 weeks, TBUT in Tabby mice gradually decreased, and it was significantly shorter than that in age-matched wild-type mice at 4, 8, 10, 12, and 16 weeks (Figure 3B). Eyelid blinking was complete in 8 -week-old Tabby mice, and the
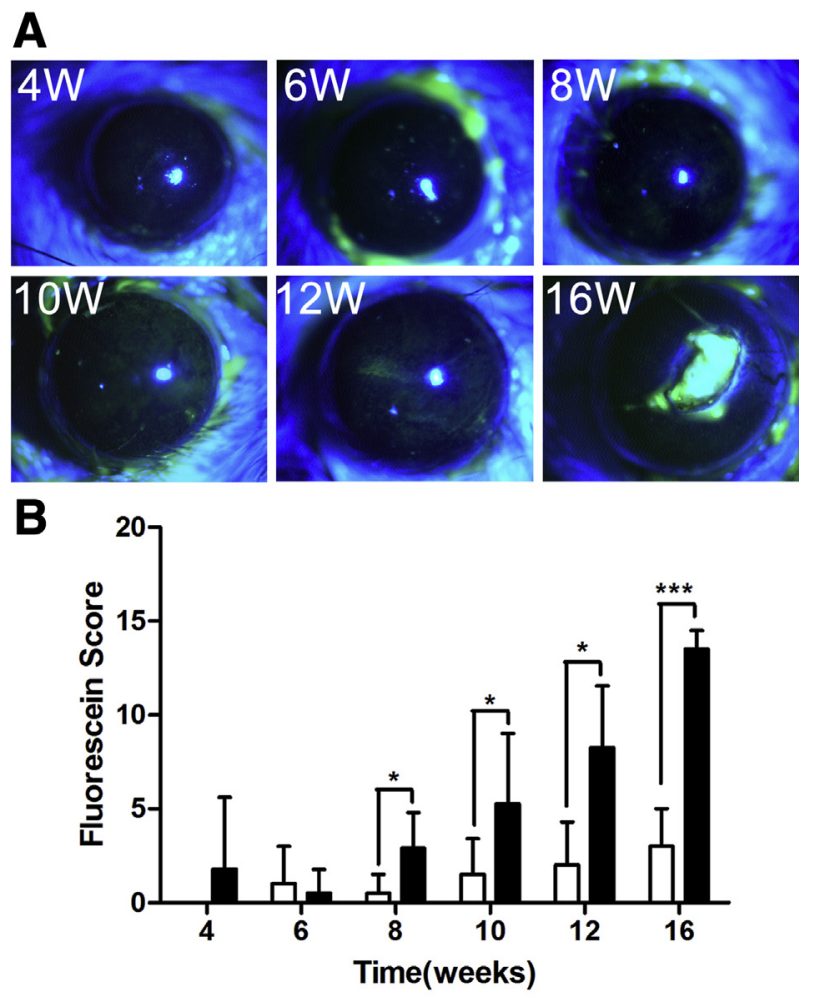

Figure 2 Fluorescein staining of TA mice ocular surface. Limited punctate corneal staining is seen at 4 and 6 weeks; however, many more appear emerged in the central cornea at 8 weeks and increase with time from 10 to 12 weeks. A: Pannus tissue at 16 weeks exhibits massive surface staining. B: The fluorescein score difference is significant between the TA mice (black bars) and the WT mice (white bars) at all of the time points from 8 to 16 week. ${ }^{*} P<0.05,{ }^{* *} P<0.001$. TA, Tabby; W, week; WT, wild-type. 

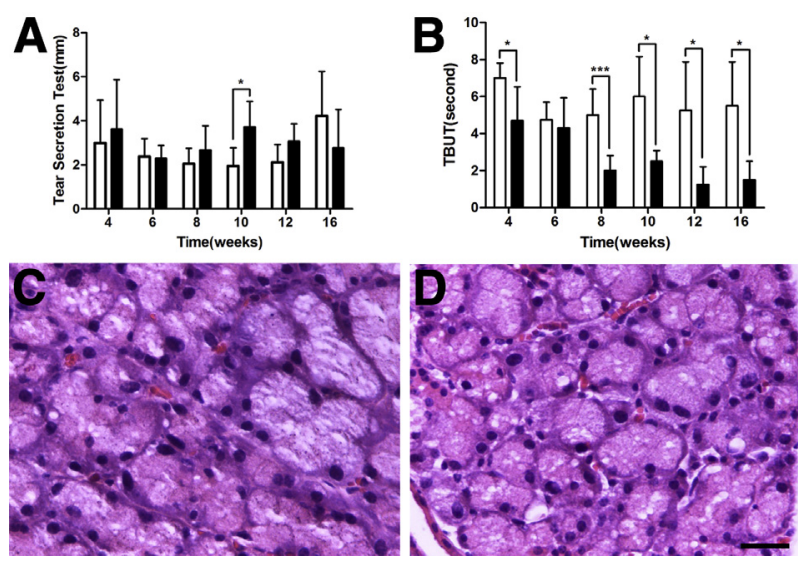

Figure 3 TA mice tear secretion and stability. Phenol red thread tear secretion test in WT and TA mice is shown from 4 to 16 weeks. A: TA mice (black bars) tear secretion is higher than that of WT mice (white bars) at 10 weeks. WT mice TBUTs remain stable from 4 to 16 weeks, whereas TA mice TBUTs gradually decrease. B: TA mice TBUT is significantly shorter at 4, 8, 10,12 , and 16 weeks. C and D: H\&E staining of the lacrimal gland tissues from 8-week-old mice shows no obvious structural difference between WT mice (C) and TA mice (D). ${ }^{\star} P<0.05,{ }^{* *} P P<0.001$. Scale bar $=50 \mu \mathrm{m}$. $\mathrm{H} \& \mathrm{E}$, hematoxylin and eosin; TA, Tabby; TBUT, tear break-up time; W, week; WT, wild-type.

blinking frequency was 2.1 blinks per minute in average, whereas it was 0.2 blink per minute in age-matched wildtype mice, as recorded by digital camera.

Ex vivo tear evaporation assay in 8-week-old mice showed different crystal patterns between age-matched wild-type mice and Tabby mice (Figure 4A), suggesting a tear component difference between the two groups. Tear smear ex vivo evaporation time was significantly shorter in Tabby mice than that in wild-type mice (Figure 4B). These results further supported the notion that tear evaporation is increased in Tabby mice. Together with TBUT, fluorescein staining, and aqueous tear secretion, the results obtained with the Tabby mice are in accord with Dry Eye WorkShop criteria established for identifying evaporative dry eye in humans. ${ }^{32}$

\section{Histology and Ocular Surface Changes}

Oil Red $\mathrm{O}$ and hematoxylin double staining showed acini gland formation in the tarsal plate of the eyelid and lipid secretion inside the acini in 4- and 8-week-old wild-type mice. In contrast, neither acinar development nor lipid formation was found in the MG loci in 4- and 8-week-old Tabby mice (Figure 5A), indicating absence of the MG in Tabby mice. ${ }^{19}$

Corneal tissue hematoxylin and eosin staining showed smooth epithelial surface was maintained in wild-type mice of both 4 and 16 weeks of age. Tabby mice also showed smooth corneal epithelial surface at 4 weeks; however; it became irregular from 6 to 10 weeks. At 12 weeks, corneal epithelial thickness increased along with prominent cell infiltration into the anterior stroma of the central cornea in Tabby mice. At 16 weeks, the pannus tissue loci in Tabby mice showed a dramatically thickened stroma with cell infiltration and neovascularization and significant stratification and keratinization of the corneal epithelium (Figure 5B).

Scanning electron microscopy of the corneal tissue identified numerous microvilli on the apical surface of the superficial epithelial cells in the wild-type mice at 4 and 8 weeks of age. In contrast, in Tabby mice at 4 weeks the microvilli were scarce and shortened. This trend became more pronounced at 8 weeks because the superficial epithelial cells became more jagged (Figure 6).

\section{Goblet Cell Distribution and Functional Changes}

Goblet cell density declines in aqueous tear-deficient dry eye. ${ }^{33,34}$ However, it is unknown whether such an effect also occurs in MGD. Periodic acid-Schiff staining in the

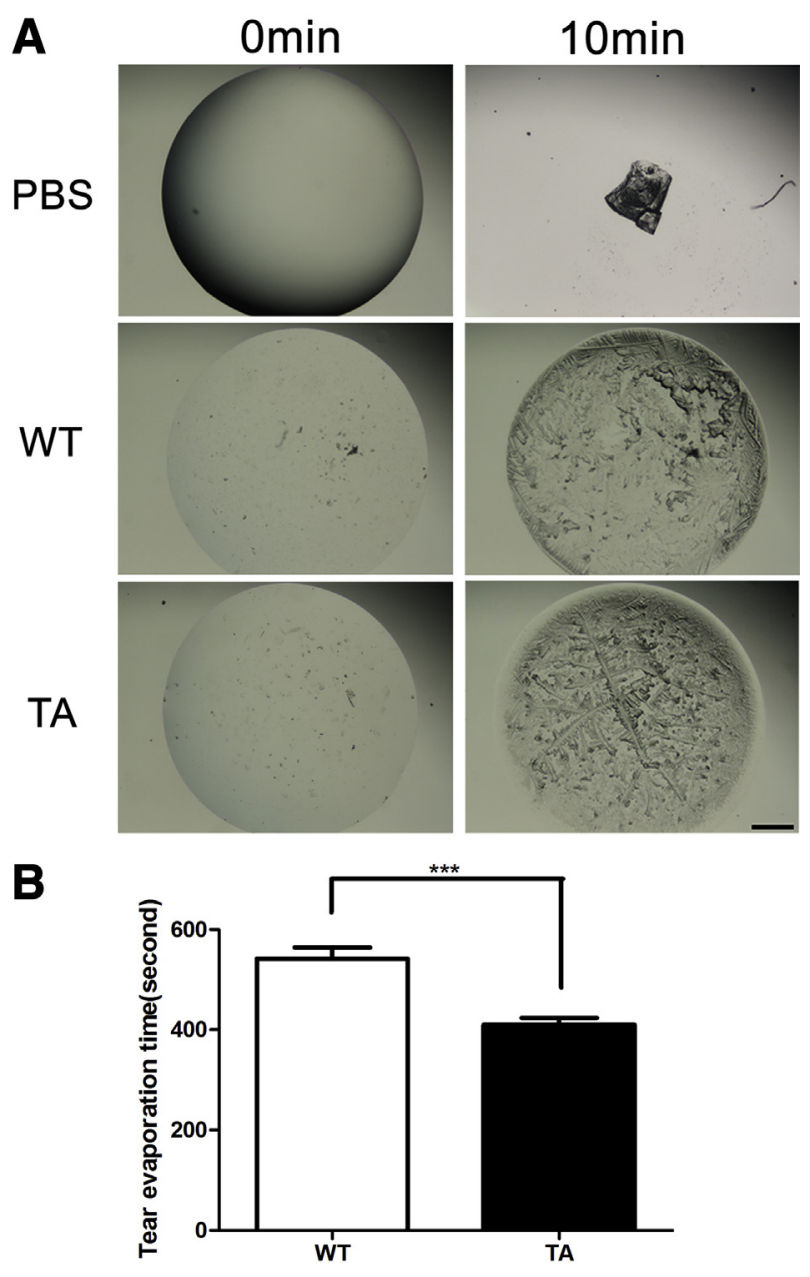

Figure 4 Ex vivo tear evaporation assay. PBS or tear mixture $(0.5 \mu \mathrm{L})$ from WT mouse and TA mouse was dripped onto a glass slide surface. A: After evaporation for 10 minutes, PBS shows single crystal formation, whereas tear mixture from WT mouse and TA mouse shows smeared crystal formation, and there is a pattern difference between tear crystals from a WT mouse and a TA mouse. B: The tear smear ex vivo evaporation time is significantly shorter in TA mice than in WT mice. ${ }^{* * *} P<0.001$. Scale bar $=500 \mu \mathrm{m}$. PBS, phosphatebuffered saline; TA, Tabby; WT, wild-type. 


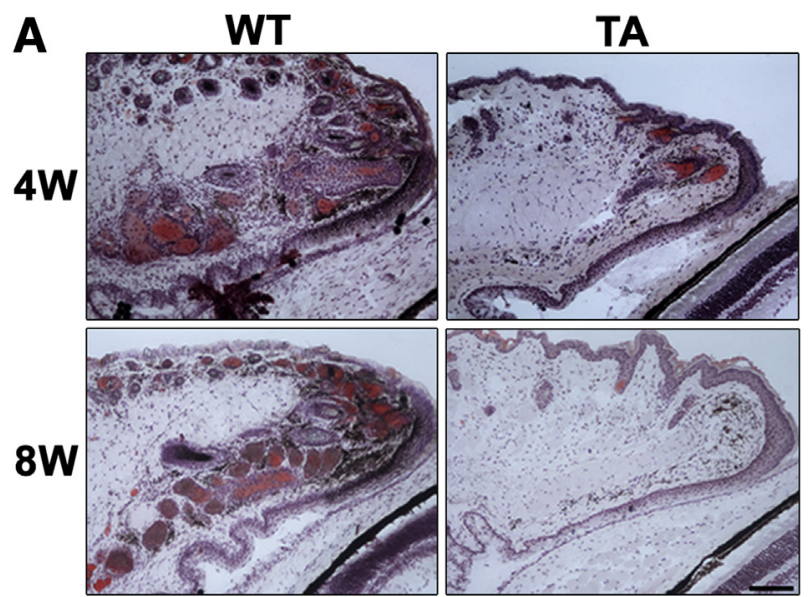

B
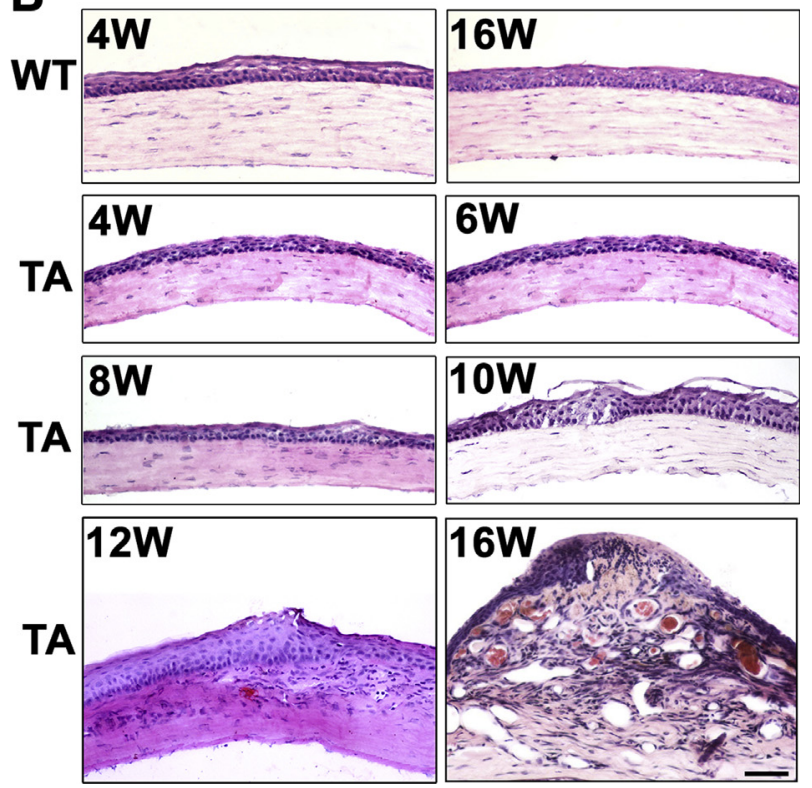

Figure 5 WT and TA mice eyelid and corneal tissue histology. A: Oil Red 0 and hematoxylin staining shows acini gland formation and lipid secretion in 4- and 8-week-old WT mice, whereas there is neither acinar development nor lipid formation in the meibomian gland loci in 4- and 8-week-old TA mice. B: H\&E staining shows smooth epithelial surfaces in both 4- and 16-week-old WT mice. TA mice show smooth corneal epithelial surface at 4 weeks, whereas it becomes jagged at 6 weeks. The rugged appearance becomes progressively more prominent at 8 and 10 weeks. At 12 weeks, corneal epithelial thickness increases, and cell infiltration is evident in the anterior stroma of the central cornea in TA mice. At 16 weeks, the pannus tissue loci in TA mice shows dramatically thickened stroma with cell infiltration and new vascularization and significant stratification of the corneal epithelium. Scale bars: $200 \mu \mathrm{m}(\mathbf{A}) ; 100 \mu \mathrm{m}$ (B). H\&E, hematoxylin and eosin; TA, Tabby; W, week; WT, wild-type.

Tabby and wild-type mice revealed that goblet cells were mainly distributed in the fornix conjunctiva. No obvious difference was found in goblet cell density between 4 - and 8 -week-old mice in the two groups (Figure 7A).

MUC5AC staining of the conjunctival tissues showed mild up-regulation in 8-week-old Tabby mice (Figure 7B). Real-time PCR of MUC5AC (Figure 7C) and MUC5B (Figure 7D) gene expression revealed that they were both significantly up-regulated in these Tabby mice, indicating that their goblet cell density did not decrease. Instead, goblet cell mucin secretion even underwent up-regulation.

\section{Aberrant Corneal Epithelial Cell Differentiation}

Squamous metaplasia is the hallmark of dry eye whereby ocular surface epithelium undergoes keratinization. ${ }^{35}$ This process is accompanied by loss of cornea-specific cytokeratin K3 and K12 expression and emergence of epidermis-specific cytokeratin K1 and K10. ${ }^{36,37}$ SPRR1B is a validated squamous metaplasia biomarker in dry eye disease. ${ }^{38}$ To thoroughly assess the development of squamous metaplasia in Tabby mice, we performed immunostaining of K12, K10, and SPRR1B on corneal tissues from 4- to 8-week-old mice. The results in Tabby mice from 4 to 8 weeks showed no obvious difference in K12 expression with that in age-matched wildtype mice (Figure 8A). K10 was not present in the corneal epithelium of 4- to 8-week-old wild-type mice, whereas in 6-week-old Tabby mice K10 expression became evident in the central corneal epithelium. By 7 weeks, its expression increased and spread, further by 8 weeks to appear throughout the full thickness of the peripheral corneal epithelium (Figure 8B). As expected, SPRR1B was not expressed in the wild-type mice corneal epithelium at any time up to 8 weeks of age. Its expression at 4 weeks was undetectable in Tabby mice, but at 5 weeks it appeared in the superficial layer of the central corneal epithelial cells. By 8 weeks, SPRR1B expression had gradually spread to the peripheral cornea and appeared throughout the entire epithelial layer (Figure 8C). Real-time PCR revealed that $K 12$ gene expression in Tabby mice instead decreased at 8 weeks of age without any apparent decrease in protein expression (Figure 8D). However, K10 (Figure 8E) and SPRR1B (Figure 8F) gene expression was

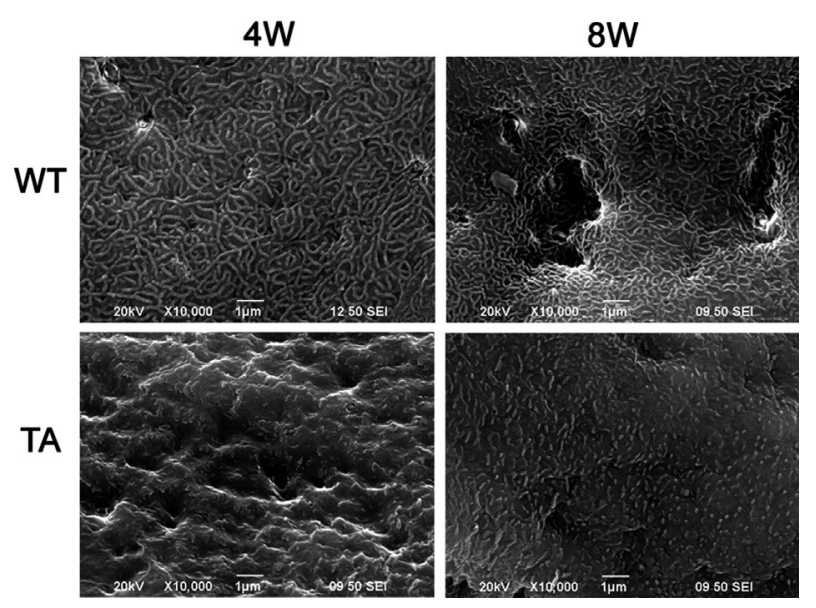

Figure 6 Corneal tissue scanning electron microscopy. Numerous microvilli are present on the apical superficial corneal epithelial cell surfaces in the WT mice at 4 and 8 weeks. In contrast, no typical microvilli formation is seen in 4- and 8-week-old TA mice whose superficial epithelial cell surfaces appeared roughened. Scale bar $=1 \mu \mathrm{m}$. TA, Tabby; W, week; WT, wild-type. 


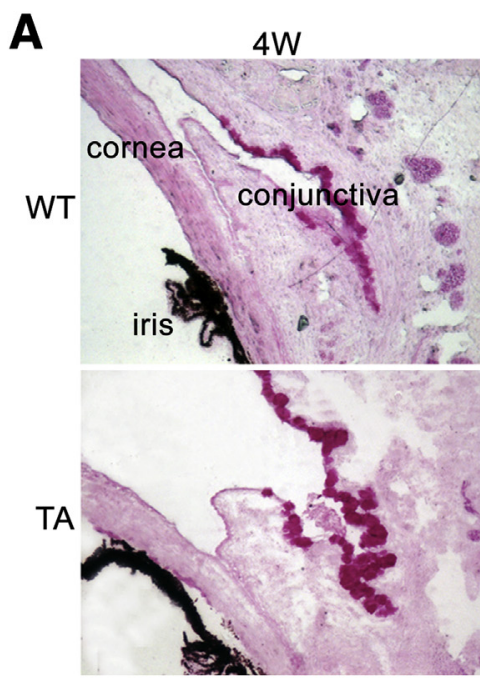

C

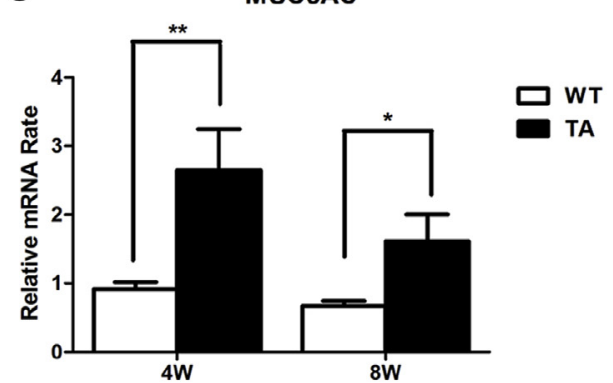

$8 \mathrm{~W}$

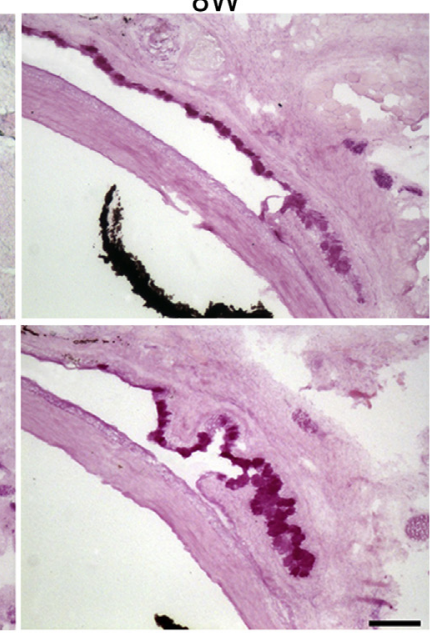

D

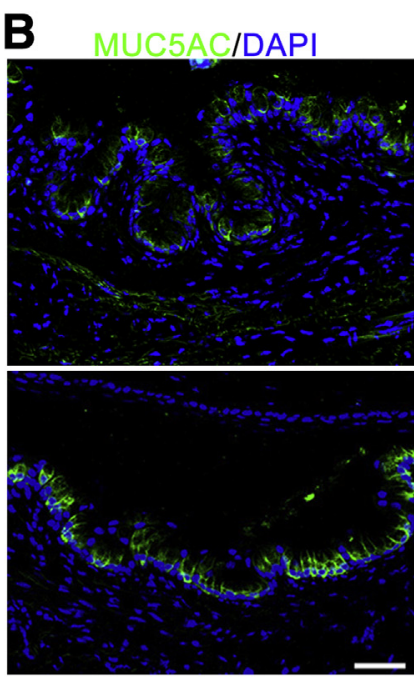

MUC5B

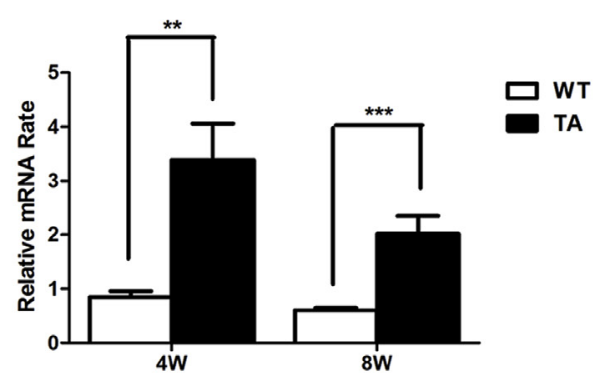

Figure 7 A: Goblet cell distribution and function. PAS staining shows that goblet cells are mainly distributed in the conjunctival fornix and there is no obvious difference in the goblet cell density of 4- and 8-week-old TA and the WT mice. B: Conjunctival tissue MUC5AC immunostaining shows mild MUC5AC up-regulation in 8-week-old TA mice. C and D: Real-time PCR shows that MUC5AC (C) and MUC5B (D) undergo up-regulation in 4- and 8-week-old TA mice. ${ }^{*} P<0.05,{ }^{* *} P<0.01$, and ${ }^{* *} P<0.001$. Scale bars: $200 \mu \mathrm{m}$ (A); $50 \mu \mathrm{m}$ (B). MUC, mucin; PAS, periodic acid-Schiff; TA, Tabby; WT, wild-type.

significantly up-regulated in the corneal epithelium of Tabby mice at 4 and 8 weeks of age.

\section{Epithelial Mucin Expression Profile Changes}

We further conducted real-time PCR on corneal epithelium and conjunctival tissues to detect mucin gene expression. The up-regulation in $\mathrm{MUCl}$ expression was evident in the cornea of Tabby mice at 4 weeks, whereas at 8 weeks of age MUC13 underwent this change (Figure 9). However, expression of MUC4 and MUC15 was invariant in the corneal epithelia. In conjunctival tissue, only MUC13 underwent up-regulation at 8 weeks of age, whereas no significant difference was found in the expression of either MUC1, MUC4, or MUC15 in 4- and 8-week-old wild-type and Tabby mice.

\section{Discussion}

MGs express and secrete into the tears a complex mixture of polar and nonpolar lipids that contain cholesteryl esters, triacylglycerol, free cholesterol, free fatty acids, phospholipids, wax esters, and diesters. ${ }^{2}$ They accumulate on the surface of the aqueous subphase of the tear film and form a lipid-enriched outer-most layer. ${ }^{39}$ This lipid-containing layer slows evaporation of the aqueous tear component, thus playing a critical role in reducing tear fluid evaporation. The major clinical indicator used to identify lipid-deficient dry eye disease is shortening of TBUT. ${ }^{4}$ Tabby mice are a relevant model of this condition because their tear film is lipid deficient because of complete MG absence. This expectation is supported by our finding that TBUT gradually decreased in Tabby mice as they aged from 4 to 16 weeks, whereas aqueous tear secretion remained relatively stable throughout this period (Figure 3, A and B). The ex vivo tear evaporation assay results support the notion that a change in tear fluid composition rather than ocular surface characteristics underlie the decline in TBUT (Figure 4, A and B). Taken together with the gradual increase in fluorescein staining scores in 8- to 16-week-old Tabby mice (Figure 2B), they are a relevant model of lipid-deficiency-induced evaporative dry eye within this time frame.

As described previously, ${ }^{19}$ we also found corneal pannus formation in most the Tabby mice at approximately 12 to 16 weeks of age (Figure 1). Such a pathologic change also was described in the adult stage of EDA gene mutant X-linked anhidrotic ectodermal dysplasia patients. ${ }^{40,41}$ However, this pathologic change is not a typical corneal damage in 

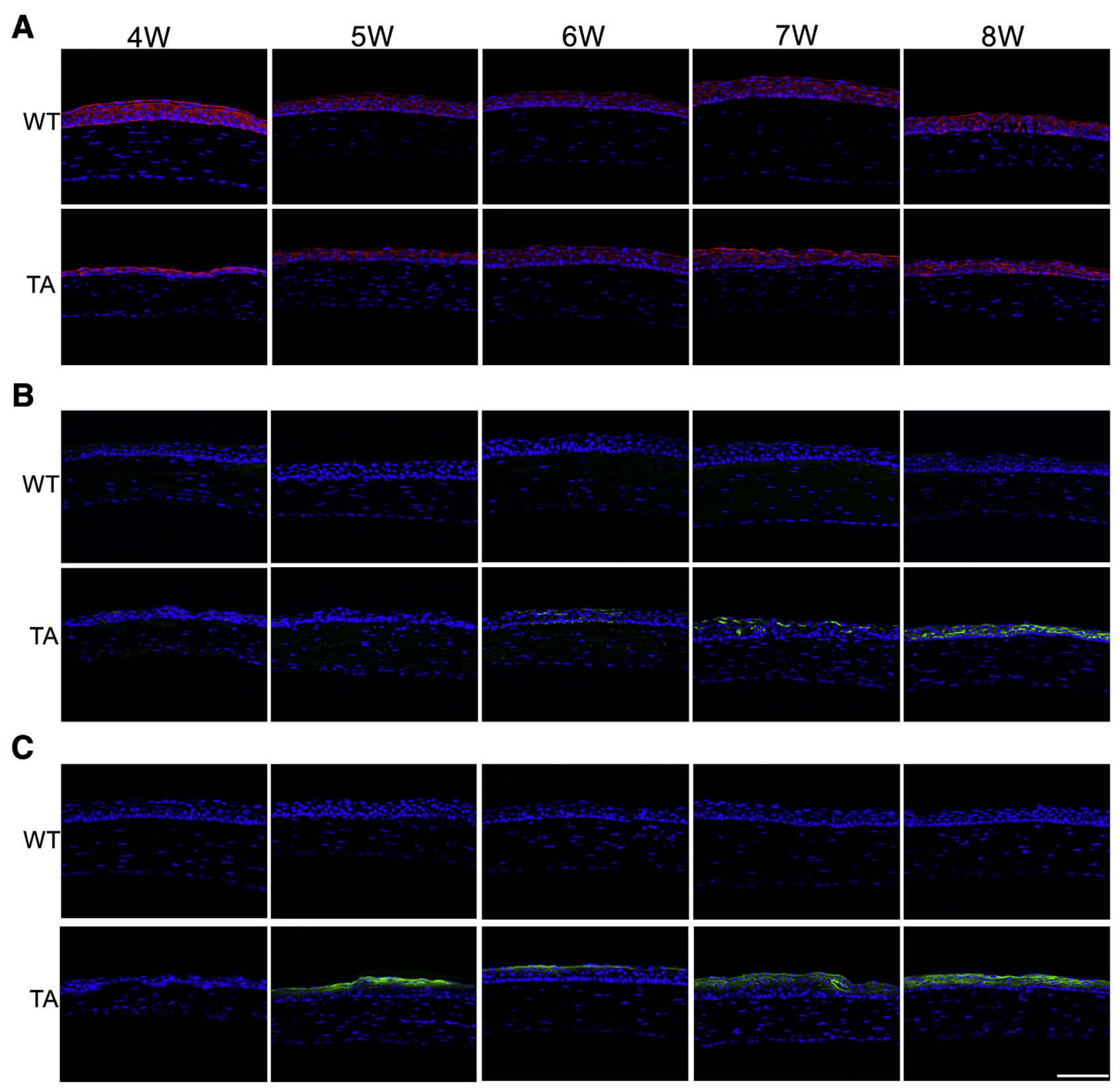

D

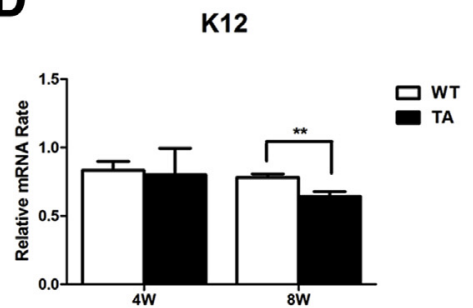

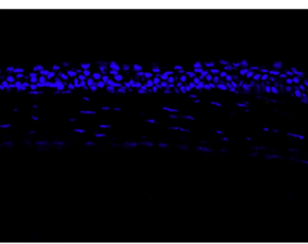
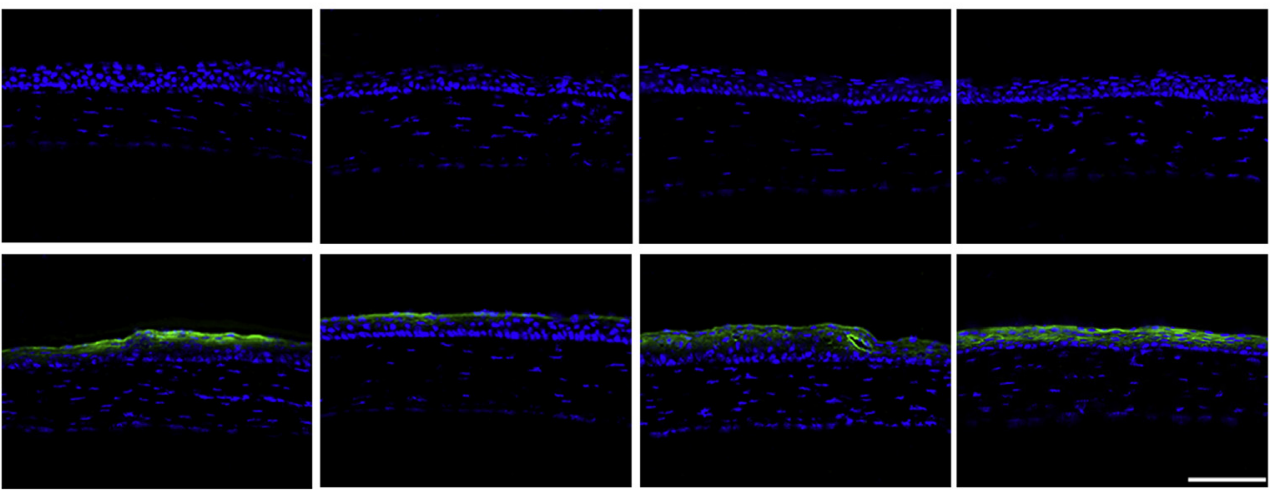

E

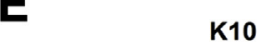

$\mathbf{F}$

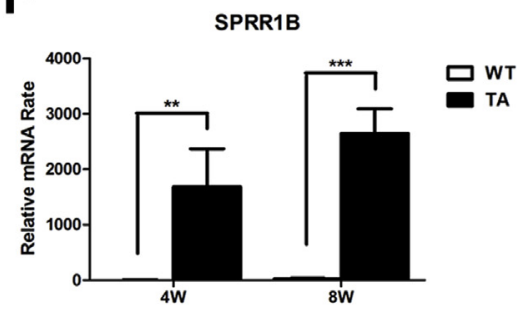

Figure 8 TA mice corneal epithelial cell differentiation. A: There is no dramatic difference in K12 expression between 4- and 8-week-old WT and TA mice. K10 is not expressed in the corneal epithelium of 4- and 8-week-old WT mice. B: In 6- and 7-week-old TA mice central corneal epithelium of K10 expression progressively increases and further spreads in 8-week-old TA mice to become evident throughout the full thickness of the peripheral corneal epithelium. C: SPRR1B expression is absent in the corneal epithelium of 4- to 8-week-old WT mice. It is negative in 4-week-old TA mice corneal epithelium, emerges in the superficial layer of the central corneal epithelial cells in 5-week-old TA mice, it increases gradually in the peripheral cornea and becomes evident throughout the full thickness of the epithelium in 8-week-old TA mice. D-F: Real-time PCR reveals that K12 expression in 8-week-old TA mice decreases (D), K10 expression (E) and SPRR1B expression (F) is significantly up-regulated in the corneal epithelium of 4 - and 8-week-old TA mice. ${ }^{*} P<0.05,{ }^{*} P<0.01$, and ${ }^{* * * P}<0.001$. Scale bars: $100 \mu \mathrm{m}$ (A-C). SPRR1B, small proline-rich protein 1B; TA, Tabby; W, week; WT, wild-type. 
Cornea
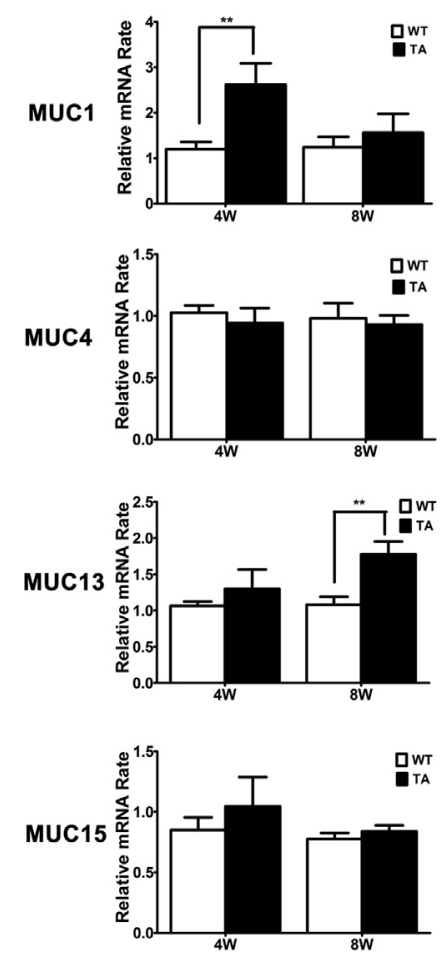

Conjunctiva
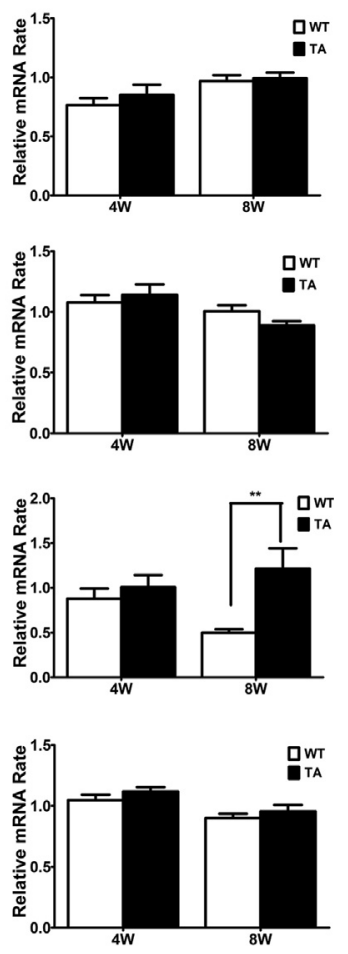

Figure 9 Corneal epithelium and conjunctival mucin expression. MUC1, MUC4, MUC13, and MUC15 expression in corneal epithelium and conjunctival tissue was determined by real-time PCR. In corneal epithelium, there is up-regulation of MUC1 in 4-week-old TA mice and MUC13 in 8-week-old TA mice. In conjunctival tissue, MUC13 is up-regulated in 8-week-old TA mice, whereas there is no significant difference in MUC1, MUC4, and MUC15 expression. ${ }^{* *} P<0.01$. MUC, mucin; TA, Tabby; W, week; WT, wild-type.

aqueous tear-deficient dry eye such as Sjögren syndrome patients. This may represent the major pathologic difference between MGD-related evaporative dry eye and aqueous tear-deficient dry eye; however; the mechanism needs to be further investigated. Cui et $\mathrm{al}^{19}$ transduced the $E D A$ gene into Tabby mice and found that corneal inflammation was largely prevented. They proposed that this rescue of ocular surface health is EDA dependent and that Tabby corneal abnormalities are not solely dependent on MG lipid secretion. In another study of ours, we detected in the MG high EDA expression and identified its gene product in the MG secretion (unpublished observation). Therefore, the lipiddeficient dry eye symptoms and disease may result from deficiencies in both lipid and protein components of the MG secretion. In addition, in the study of Cui et al. ${ }^{19}$ about Tabby mice EDA gene transduction, the corneas still appeared somewhat abnormal. This result suggests that MG contribution to tear film stability is more complex than that provided by $E D A$ gene expression. Evidence is emerging that specific proteins present in the MG secretion play a role in tear lipid layer formation and stabilization. ${ }^{3}$ Further study is needed to identify which proteins that form adducts with lipids contribute to maintaining ocular surface health.

In our study, hematoxylin and eosin staining revealed that the corneal epithelial surface in Tabby mice appeared as a less smooth surface from the fourth week of age (Figure 5B). This change was accompanied by a dramatic decrease in microvilli, giving the apical epithelial surface an irregular appearance (Figure 6). It was reported that microvilli surface density can be used as a monitor of progressive changes in corneal surface integrity caused by exposure to desiccating dry eye conditions. ${ }^{42}$ Declines in microvilli size and density were also found to accompany benzalkonium chloride-induced dry eye development in mice. ${ }^{31}$ To the best of our knowledge, the present report is the first one to describe epithelial surface structure change in MGD-related dry eye. However, the mechanism of microvilli change in Tabby mice needs to be further investigated. It may be a result of lipid and/or protein deficiency of the MG secretion. The shortening of microvilli may reduce mucin binding, thus increasing tear film surface tension, and reducing its surface spreading, which may contribute to TBUT shortening in Tabby mice.

Goblet cell density decreases in aqueous tear-deficient dry eye $^{32}$ and benzalkonium chloride-induced dry eye animal models. ${ }^{31,43,44}$ In the present study, periodic acid-Schiff staining showed that goblet cell density in Tabby mice did not decrease (Figure 7A). Furthermore, immunostaining even showed that MUC5AC expression increased at 8 weeks of age (Figure 7B), which is consistent with increases in MUC5AC and MUC5B gene expression in Tabby mice at 4 and 8 weeks (Figure 7, C and D). The other four major mucin expression levels we evaluated were not downregulated. MUC13 gene expression instead increased both in cornea and conjunctiva in 8-week-old Tabby mice (Figure 9). We propose that MUC5AC up-regulation may be a compensatory response triggered by lipid deficiency in the Tabby mice. Moreover, goblet cell reaction may be different in aqueous tear-deficient dry eye and lipid-deficient dry eye.

Squamous metaplasia is a common pathologic process in aqueous tear-deficient dry eye. ${ }^{35}$ This condition arises from abnormal differentiation of the corneal epithelium into a keratinized skin epithelial phenotype. ${ }^{36,45,46}$ We found that K12 gene expression decreased significantly in Tabby mice at 8 weeks of age, although this did not correspond with invariant K12 protein expression at that time (Figure 8, A and D). However, K10 expression was detected in the corneal epithelium in 6-week-old mice, and its gene and protein expressions progressively increased, supporting the notion of abnormal corneal epithelial differentiation (Figure 8, B and E). We also found SPRR1B, a stressinduced transcript, was elicited at 5 weeks in the central corneal superficial epithelium and gradually spread into all layers of the peripheral corneal epithelium in 8-week-old Tabby mice (Figure $8 \mathrm{C}$ ). The temporal and spatial expression pattern of SPRR1B precisely matches the pathologic process underlying corneal epithelial changes in evaporative dry eye. SPRR1B up-regulation occurs in both evaporative and immune-mediated aqueous tear-deficient dry eye disease and was designated a squamous metaplasia biomarker. ${ }^{47}$ Our results indicate that cornea epithelial metaplasia occurs at an 
early stage in MGD-related dry eye before a significant change in K12 expression. This is also the first description of MGD-related evaporative dry eye-induced corneal epithelial squamous metaplasia in an animal model. However, in a previous study, dealing with MGD-related lipid tear deficiency, impression cytology of patients did not identify prominent squamous metaplasia. ${ }^{48}$ Therefore, probing instead for SPRR1B transcripts may be a sensitive early-stage corneal squamous metaplasia biomarker in MGD-related evaporative dry eye.

In summary, we show here in Tabby mice that the tear film and ocular surface epithelial changes that result from the absence of MGs mimic to a certain extent those described in MGD-related evaporative dry eye patients. This correspondence suggests that Tabby mice may provide a relevant model of lipid-deficient dry eye disease. Because MGD has become the most common cause of dry eye, demand is increasing to develop lipid tear substitutes for treating this condition, the application of these mice may contribute to efforts that evaluate novel pharmacologic classes in treating MGD-related dry eye.

\section{Acknowledgments}

We thank Dr. Peter Sol Reinach for his critical reading and valuable suggestions on the manuscript.

Y.-C.W., S.L., X.C., and W.L. conceived and designed the experiments; Y.-C.W., S.L., X.C., B.M., H.H., T.L., J.Y., and L.Z. performed the experiments; Y.-C.W., S.L., X.C., Y.C., Z.L., and W.L. analyzed the data; Z.L. and W.L. contributed reagents, materials, and analysis tools; and Y.-C.W., X.C., B.M., and W.L. wrote the manuscript.

\section{References}

1. Asbell PA, Stapleton FJ, Wickstrom K, Akpek EK, Aragona P, Dana R, Lemp MA, Nichols KK: The international workshop on meibomian gland dysfunction: report of the clinical trials subcommittee. Invest Ophthalmol Vis Sci 2011, 52:2065-2085

2. Butovich IA, Uchiyama E, McCulley JP: Lipids of human meibum: mass-spectrometric analysis and structural elucidation. J Lipid Res 2007, 48:2220-2235

3. Tsai PS, Evans JE, Green KM, Sullivan RM, Schaumberg DA, Richards SM, Dana MR, Sullivan DA: Proteomic analysis of human meibomian gland secretions. Br J Ophthalmol 2006, 90:372-377

4. Holly FJ, Lemp MA: Tear physiology and dry eyes. Surv Ophthalmol 1977, 22:69-87

5. Nelson JD, Shimazaki J, Benitez-del-Castillo JM, Craig JP, McCulley JP, Den S, Foulks GN: The international workshop on meibomian gland dysfunction: report of the definition and classification subcommittee. Invest Ophthalmol Vis Sci 2011, 52:1930-1937

6. Nichols KK, Foulks GN, Bron AJ, Glasgow BJ, Dogru M, Tsubota K, Lemp MA, Sullivan DA: The international workshop on meibomian gland dysfunction: executive summary. Invest Ophthalmol Vis Sci 2011, 52:1922-1929

7. Bron AJ, Tiffany JM, Gouveia SM, Yokoi N, Voon LW: Functional aspects of the tear film lipid layer. Exp Eye Res 2004, 78:347-360

8. Bron AJ, Tiffany JM: The contribution of meibomian disease to dry eye. Ocul Surf 2004, 2:149-165
9. Foulks GN, Bron AJ: Meibomian gland dysfunction: a clinical scheme for description, diagnosis, classification, and grading. Ocul Surf 2003, $1: 107-126$

10. Gilbard JP, Rossi SR, Heyda KG: Tear film and ocular surface changes after closure of the meibomian gland orifices in the rabbit. Ophthalmology 1989, 96:1180-1186

11. Jester JV, Nicolaides N, Kiss-Palvolgyi I, Smith RE: Meibomian gland dysfunction. II. The role of keratinization in a rabbit model of MGD. Invest Ophthalmol Vis Sci 1989, 30:936-945

12. Jester JV, Rife L, Nii D, Luttrull JK, Wilson L, Smith RE: In vivo biomicroscopy and photography of meibomian glands in a rabbit model of meibomian gland dysfunction. Invest Ophthalmol Vis Sci 1982, 22:660-667

13. Lambert R, Smith RE: Hyperkeratinization in a rabbit model of meibomian gland dysfunction. Am J Ophthalmol 1988, 105:703-705

14. Lambert RW, Smith RE: Pathogenesis of blepharoconjunctivitis complicating 13-cis-retinoic acid (isotretinoin) therapy in a laboratory model. Invest Ophthalmol Vis Sci 1988, 29:1559-1564

15. Ohnishi Y, Kohno T: Polychlorinated biphenyls poisoning in monkey eye. Invest Ophthalmol Vis Sci 1979, 18:981-984

16. Yagyu H, Kitamine T, Osuga J, Tozawa R, Chen Z, Kaji Y, Oka T, Perrey S, Tamura Y, Ohashi K, Okazaki H, Yahagi N, Shionoiri F, Iizuka Y, Harada K, Shimano H, Yamashita H, Gotoda T, Yamada N, Ishibashi S: Absence of ACAT-1 attenuates atherosclerosis but causes dry eye and cutaneous xanthomatosis in mice with congenital hyperlipidemia. J Biol Chem 2000, 275:21324-21330

17. Naito A, Yoshida H, Nishioka E, Satoh M, Azuma S, Yamamoto T, Nishikawa S, Inoue J: TRAF6-deficient mice display hypohidrotic ectodermal dysplasia. Proc Natl Acad Sci U S A 2002, 99:8766-8771

18. House JS, Zhu S, Ranjan R, Linder K, Smart RC: C/EBPalpha and C/EBPbeta are required for Sebocyte differentiation and stratified squamous differentiation in adult mouse skin. PLoS One 2010, 5: e9837

19. Cui CY, Smith JA, Schlessinger D, Chan CC: X-linked anhidrotic ectodermal dysplasia disruption yields a mouse model for ocular surface disease and resultant blindness. Am J Pathol 2005, 167:89-95

20. Huang J, Dattilo LK, Rajagopal R, Liu Y, Kaartinen V, Mishina Y, Deng CX, Umans L, Zwijsen A, Roberts AB, Beebe DC: FGF-regulated BMP signaling is required for eyelid closure and to specify conjunctival epithelial cell fate. Development 2009, 136:1741-1750

21. Plikus M, Wang WP, Liu J, Wang X, Jiang TX, Chuong CM: Morphoregulation of ectodermal organs: integument pathology and phenotypic variations in K14-Noggin engineered mice through modulation of bone morphogenic protein pathway. Am J Pathol 2004, 164:1099-1114

22. Tsau C, Ito M, Gromova A, Hoffman MP, Meech $\mathrm{R}$, Makarenkova HP: Barx2 and Fgf10 regulate ocular glands branching morphogenesis by controlling extracellular matrix remodeling. Development 2011, 138:3307-3317

23. Kenchegowda D, Swamynathan S, Gupta D, Wan H, Whitsett J, Swamynathan SK: Conditional disruption of mouse Klf5 results in defective eyelids with malformed meibomian glands, abnormal cornea and loss of conjunctival goblet cells. Dev Biol 2011, 356:5-18

24. Lin MH, Hsu FF, Miner JH: Requirement of fatty acid transport protein 4 for development, maturation, and function of sebaceous glands in a mouse model of ichthyosis prematurity syndrome. J Biol Chem 2013, 288:3964-3976

25. Jong MC, Gijbels MJ, Dahlmans VE, Gorp PJ, Koopman SJ, Ponec M, Hofker MH, Havekes LM: Hyperlipidemia and cutaneous abnormalities in transgenic mice overexpressing human apolipoprotein $\mathrm{C} 1$. J Clin Invest 1998, 101:145-152

26. Miyazaki M, Man WC, Ntambi JM: Targeted disruption of stearoylCoA desaturase 1 gene in mice causes atrophy of sebaceous and meibomian glands and depletion of wax esters in the eyelid. J Nutr 2001, 131:2260-2268

27. Zheng Y, Eilertsen KJ, Ge L, Zhang L, Sundberg JP, Prouty SM, Stenn KS, Parimoo S: Scd1 is expressed in sebaceous glands and is disrupted in the asebia mouse. Nat Genet 1999, 23:268-270 
28. Srivastava AK, Pispa J, Hartung AJ, Du Y, Ezer S, Jenks T, Shimada T, Pekkanen M, Mikkola ML, Ko MS, Thesleff I, Kere J, Schlessinger D: The Tabby phenotype is caused by mutation in a mouse homologue of the EDA gene that reveals novel mouse and human exons and encodes a protein (ectodysplasin-A) with collagenous domains. Proc Natl Acad Sci U S A 1997, 94:13069-13074

29. Gruneberg H: The glandular aspects of the tabby syndrome in the mouse. J Embryol Exp Morphol 1971, 25:1-19

30. Association for Research in Vision and Ophthalmology: Statement for the Use of Animals in Ophthalmic and Visual Research. Copyright, 2015, Association for Research in Vision and Ophthalmology, Rockville, MD. Available at http://www.arvo.org/about_arvo/policies/statement_for_ the_use_of_animals_in_ophthalmic_and_visual_research

31. Lin Z, Liu X, Zhou T, Wang Y, Bai L, He H, Liu Z: A mouse dry eye model induced by topical administration of benzalkonium chloride. Mol Vis 2011, 17:257-264

32. The definition and classification of dry eye disease: report of the Definition and Classification Subcommittee of the International Dry Eye WorkShop (2007). Ocul Surf 2007, 5:75-92

33. Nelson JD, Wright JC: Conjunctival goblet cell densities in ocular surface disease. Arch Ophthalmol 1984, 102:1049-1051

34. Zhang X, De Paiva CS, Su Z, Volpe EA, Li DQ, Pflugfelder SC: Topical interferon-gamma neutralization prevents conjunctival goblet cell loss in experimental murine dry eye. Exp Eye Res 2014, 118:117-124

35. Tseng SC: Staging of conjunctival squamous metaplasia by impression cytology. Ophthalmology 1985, 92:728-733

36. Tseng SC, Hatchell D, Tierney N, Huang AJ, Sun TT: Expression of specific keratin markers by rabbit corneal, conjunctival, and esophageal epithelia during vitamin A deficiency. J Cell Biol 1984, 99:2279-2286

37. Nakamura T, Nishida K, Dota A, Matsuki M, Yamanishi K, Kinoshita S: Elevated expression of transglutaminase 1 and keratinization-related proteins in conjunctiva in severe ocular surface disease. Invest Ophthalmol Vis Sci 2001, 42:549-556

38. Li S, Nikulina K, DeVoss J, Wu AJ, Strauss EC, Anderson MS, McNamara NA: Small proline-rich protein 1B (SPRR1B) is a biomarker for squamous metaplasia in dry eye disease. Invest Ophthalmol Vis Sci 2008, 49:34-41

39. McCulley JP, Shine W: A compositional based model for the tear film lipid layer. Trans Am Ophthalmol Soc 1997, 95:79-88. discussion 88-93

40. Tyagi P, Tyagi V, Hashim AA: Ocular and non-ocular manifestations of hypohidrotic ectodermal dysplasia. BMJ Case Rep 2011, 2011

41. Kaercher T: Ocular symptoms and signs in patients with ectodermal dysplasia syndromes. Graefes Arch Clin Exp Ophthalmol 2004, 242: 495-500

42. Julio G, Merindano MD, Canals M, Caum C, Rallo M: Indicators of progressive corneal exposure to dry eye conditions. Optom Vis Sci 2012, 89:1042-1049

43. Li C, Song Y, Luan S, Wan P, Li N, Tang J, Han Y, Xiong C, Wang Z: Research on the stability of a rabbit dry eye model induced by topical application of the preservative benzalkonium chloride. PLoS One 2012, 7:e33688

44. Xiong C, Chen D, Liu J, Liu B, Li N, Zhou Y, Liang X, Ma P, Ye C, Ge J, Wang Z: A rabbit dry eye model induced by topical medication of a preservative benzalkonium chloride. Invest Ophthalmol Vis Sci 2008, 49:1850-1856

45. Li W, Chen YT, Hayashida Y, Blanco G, Kheirkah A, He H, Chen SY, Liu CY, Tseng SC: Down-regulation of Pax6 is associated with abnormal differentiation of corneal epithelial cells in severe ocular surface diseases. J Pathol 2008, 214:114-122

46. Li W, Hayashida Y, Chen YT, He H, Tseng DY, Alonso M, Chen SY, Xi X, Tseng SC: Air exposure induced squamous metaplasia of human limbal epithelium. Invest Ophthalmol Vis Sci 2008, 49:154-162

47. Li S, Gallup M, Chen YT, McNamara NA: Molecular mechanism of proinflammatory cytokine-mediated squamous metaplasia in human corneal epithelial cells. Invest Ophthalmol Vis Sci 2010, 51: $2466-2475$

48. Lee SH, Tseng SC: Rose bengal staining and cytologic characteristics associated with lipid tear deficiency. Am J Ophthalmol 1997, 124 $736-750$ 